\title{
Evolution of Immune Systems From Viruses and Transposable Elements
}

\author{
Felix Broecker ${ }^{*}$ and Karin Moelling ${ }^{2,3}$ \\ ${ }^{1}$ Department of Microbiology, Icahn School of Medicine at Mount Sinai, New York, NY, United States, ${ }^{2}$ Institute of Medical \\ Microbiology, University of Zurich, Zurich, Switzerland, ${ }^{3}$ Max Planck Institute for Molecular Genetics, Berlin, Germany
}

Virus-derived sequences and transposable elements constitute a substantial portion of many cellular genomes. Recent insights reveal the intimate evolutionary relationship between these sequences and various cellular immune pathways. At the most basic level, superinfection exclusion may be considered a prototypical virus-mediated immune system that has been described in both prokaryotes and eukaryotes. More complex immune mechanisms fully or partially derived from mobile genetic elements include CRISPR-Cas of prokaryotes and the RAG1/2 system of vertebrates, which provide immunological memory of foreign genetic elements and generate antibody and $T$ cell receptor diversity, respectively. In this review, we summarize the current knowledge on the contribution of mobile genetic elements to the evolution of cellular immune pathways. A picture is emerging in which the various cellular immune systems originate from and are spread by viruses and transposable elements. Immune systems likely

OPEN ACCESS

Edited by:

Gustavo Caetano-Anollés,

University of Illinois

at Urbana-Champaign, United States

Reviewed by:

Dino McMahon,

Freie Universität Berlin, Germany

Alan Richard Davidson,

University of Toronto, Canada

${ }^{*}$ Correspondence:

Felix Broecker

felixbroecker@gmx.net

Specialty section:

This article was submitted to

Virology,

a section of the journa

Frontiers in Microbiology

Received: 04 November 2018

Accepted: 14 January 2019

Published: 29 January 2019

Citation:

Broecker F and Moelling K (2019) Evolution of Immune Systems From

Viruses and Transposable Elements.

Front. Microbiol. 10:51.

doi: 10.3389/fmicb.2019.00051 evolved from simple superinfection exclusion to highly complex defense strategies.

Keywords: transposable elements, mobile genetic elements, viruses, superinfection exclusion, immune system, CRISPR-Cas, antibodies, RNase H

\section{INTRODUCTION}

Cellular organisms have co-evolved with various mobile genetic elements (MGEs), including transposable elements (TEs), retroelements and viruses, many of which can integrate into the host DNA. MGEs constitute $~ 50 \%$ of mammalian genomes, $>70 \%$ of some plant genomes and up to $30 \%$ of bacterial genomes (Koonin and Krupovic, 2015). The evolutionary interplay between MGEs and their hosts has generated a plethora of cellular defense mechanisms and countermeasures. Notably, many immune systems, or parts thereof, including the prokaryotic CRISPRCas mechanism and antibody/T cell receptor (TCR) diversification by $\mathrm{V}(\mathrm{D}) \mathrm{J}$ recombination in vertebrates have been recruited from viruses or other MGEs. Here, we summarize the current knowledge on the evolution of diverse immune systems of prokaryotes and eukaryotes, highlighting a general scenario for the origin of cellular defense systems from MGEs. A non-exhaustive overview of different cellular immune systems is presented in Figure 1.

\section{VIRUSES AGAINST VIRUSES: SUPERINFECTION EXCLUSION AS A MECHANISM OF ANTIVIRAL IMMUNITY}

Superinfection exclusion (SIEx) is the ability of a preexisting viral infection to restrict secondary infections, often by the same or a closely related virus. SIEx was first observed in tobacco plants that, when pre-infected with a mild variant of Tobacco mosaic virus (TMV), were protected against a virulent TMV strain (McKinney, 1929). SIEx was later found to be common for many other systems, 
including viruses of bacteria, animals, humans, and plants (Moelling et al., 2017). The cellular organism benefits from SIEx if a preexisting infection with a non-pathogenic or mildly pathogenic virus protects against detrimental viruses. Thus, SIEx can be regarded as a simple adaptive immune system, which is inheritable if the first virus integrates into the cellular genome or is transmitted to the progeny by other means. One recent experimentally verified example is Mavirus, a virophage that integrates into the genome of Cafeteria roenbergensis and protects the flagellate organism from infection with a deadly virus (Fischer and Hackl, 2016). This example is further described below.

An evolutionarily early immune system may have been constituted by viroids or viroid-like RNAs. Viroids are virusrelated, protein-free infectious agents consisting of highly structured, circular non-coding RNA that can be catalytically active through ribozyme activity (Flores et al., 2014). They may be remnants of the ancient RNA world thought to have existed before the evolution of DNA or proteins (Diener, 1989; Flores et al., 2014). However, the fact that extant viroids have so far only been identified in plants (with the notable exception of hepatitis delta virus, a derivative of a viroid with a short insert of protein-coding capacity) suggests their appearance after the last universal cellular ancestor (Koonin and Dolja, 2014). Regardless, viroids likely recapitulate principal features of selfish elements of the ancient RNA world. In plants, SIEx has been described between mild and severe strains of the same viroid as well as between different viroids (Kovalskaya and Hammond, 2014). The mechanisms of SIEx in plants may include RNA interference (RNAi), with siRNAs produced by Dicer from the first infecting viroid acting against the superinfecting one. It remains unclear, however, how the first viroid escapes RNAi; it may associate with protecting host factors or its localization in the nucleus or chloroplasts protects from RNAi, which mainly acts in the cytoplasm (Kovalskaya and Hammond, 2014). It seems likely that SIEx existed before the evolution of complex viruses or cellular immune systems such as RNAi. In the ancient RNA world, a simple RNA-based immune system could have been constituted of a ribozyme/viroid that prevents superinfection with another one via ribozymatic cleavage in trans (Figure 1). Although known natural ribozymes/viroids are generally selfcleaving, they can be modified relatively easily to yield transcleaving derivatives (Jimenez et al., 2015), suggesting that trans-cleaving ribozymes may have existed or may still exist naturally.

\section{INTEGRATED VIRAL SEQUENCES ACT AS INHERITABLE IMMUNITY IN PROKARYOTES}

Insertion of viral genomes, or parts thereof, into host genomes is at the origin of many immune systems (Moelling et al., 2017). Integration of prophages into bacterial genomes is often associated with a fitness cost to the host (Iranzo et al., 2017), however, prophages can mediate resistance to infection by exogenous bacteriophages (phages) through various mechanisms. For example, the prophage-encoded Tip protein inhibits formation of type IV pili on the surface of Pseudomonas aeruginosa (Chung et al., 2014). Since these pili are common phage receptors, Tip expression mediates SIEx to various phages (Bondy-Denomy et al., 2016). Interestingly, prophage-mediated alteration of type IV pili function has little or no fitness cost to the host. In $P$. aeruginosa, three prophages are sufficient to mediate resistance against at least 30 different phages. Various other mechanisms of prophage-mediated protection against exogenous phages have been reported in multiple bacterial species, which include cell surface alterations, receptor blockade and transcriptional repression (Bondy-Denomy and Davidson, 2014).

CRISPR-Cas provides another prokaryotic adaptive immune system. Here, a fragment of DNA (or reverse-transcribed RNA) of an infecting phage or other foreign genetic elements is integrated as spacer into a CRISPR array in the host genome (Hille et al., 2018). Thereby, spacers act as immunological memory for long-term protection of the cell and future generations. The transcribed CRISPR array RNA (pre-crRNA) is processed into smaller crRNAs that guide sequence-specific cleavage of homologous invading nucleic acids by Cas effector nucleases. A common feature of all Type II and Type V effector nucleases, Cas9 and Cas12a, respectively, is a ribonuclease $\mathrm{H}$ (RNase $\mathrm{H})$-like RuvC domain that cleaves the non-complementary DNA strand, whereas an HNH nuclease (Cas9) or a NUC domain (Cas12a) cleaves the complementary DNA strand of the target dsDNA (Makarova et al., 2017). Other Cas effectors utilize different nuclease domains, such as histidineaspartate nucleases. CRISPR arrays are found in about half of bacterial and nearly $90 \%$ of archaeal genomes (Hille et al., 2018).

At least four different MGEs were involved in the evolution of CRISPR-Cas systems (Koonin and Makarova, 2017). First, the adaptation module of all CRISPR-Cas systems, responsible for spacer acquisition, originated from casposons (a fusion word between Cas and transposons), TEs that utilize Cas1 nuclease for DNA integration (Krupovic et al., 2014). Second, the Cas2 nuclease, which could have been present also in the casposon, as well as HEPN family RNases found in several other Cas proteins likely originate from toxin-antitoxin (TA) modules (Koonin and Krupovic, 2015). Although TA modules do not encode their own mobility genes, they can be regarded as MGEs, as they are typically transferred by plasmids (Koonin and Makarova, 2017). Third, many Type III CRISPR-Cas systems recruited the reverse transcriptase (RT) from a mobile group II intron, which allows for spacer acquisition from invading RNA. Fourth, the RuvC domains of Type II and Type V systems were likely derived from TnpB nucleases of DNA transposons. A complete, functional CRISPR-Cas system encoded by a phage has been reported (Seed et al., 2013), suggesting that phages may also serve as vehicles for horizontal gene transfer (HGT) of this kind of immune system. Both prophage-mediated SIEx and CRISPR-Cas can be regarded as adaptive prokaryotic immune systems that generate immunological memory to protect the cell and future generations against viral infections. CRISPR-Cas acquired specific immunity can be transmitted 


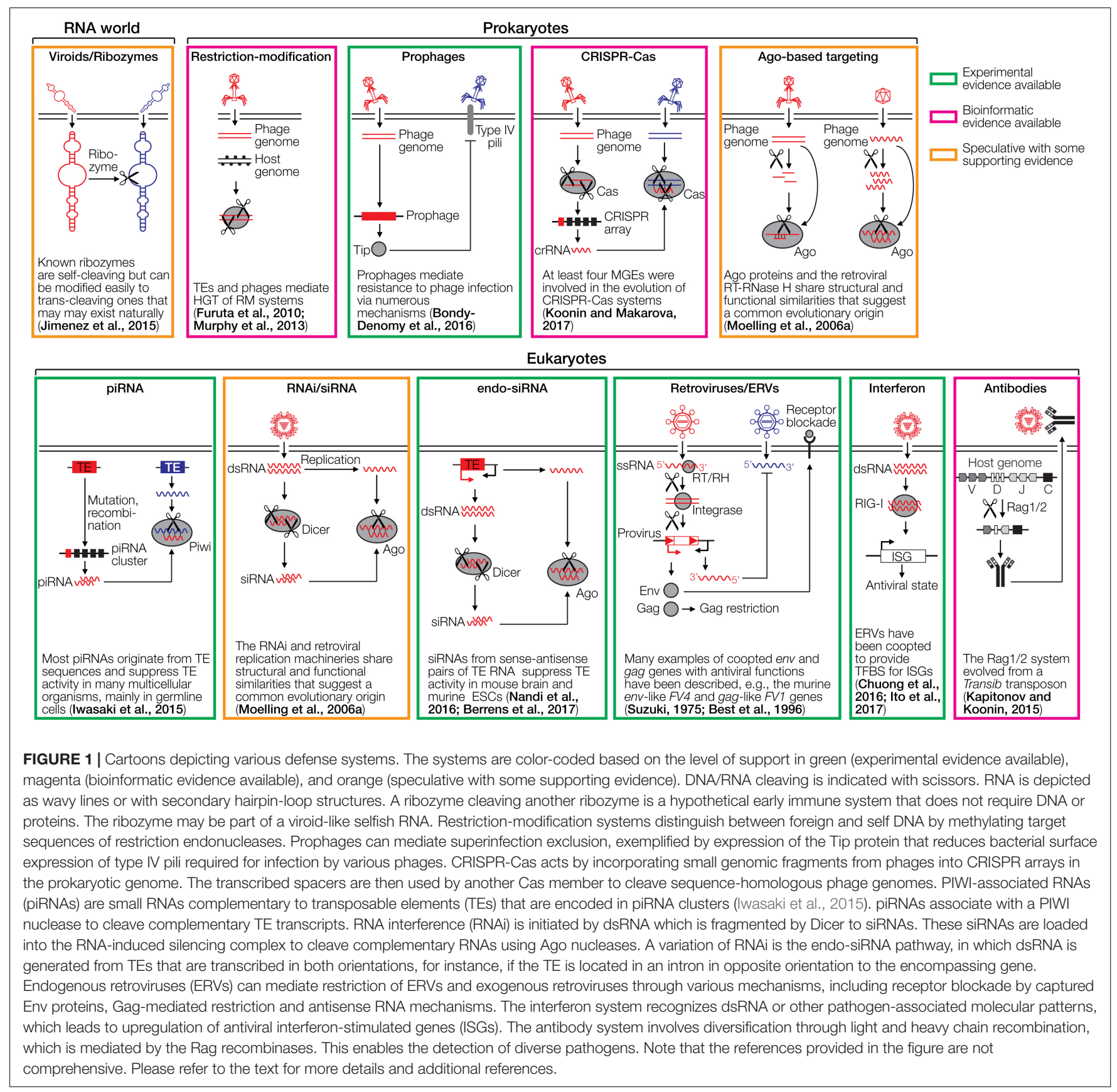

across thousands of microbial generations (Weinberger et al., 2012).

\section{BACTERIAL IMMUNE SYSTEMS CO-LOCALIZE WITH VIRAL AND TRANSPOSABLE ELEMENT SEQUENCES}

Restriction-modification (RM) systems consist of two components; a restriction endonuclease that cleaves invading double-stranded DNA (e.g., of phage origin) by recognizing a short DNA motif and a methylase that masks that motif on the prokaryote's genome by introducing methyl groups to prevent destruction of its own DNA. Since the recognition motifs are usually short and thereby likely to be present on the majority of invading DNA molecules, RM systems can be regarded as a prokaryotic innate immune system. The various restriction endonucleases of RM systems likely evolved from one or a few common ancestor(s) (Jeltsch et al., 1995) and became widespread via HGT (Jeltsch and Pingoud, 1996). RM systems are encoded by about $90 \%$ of prokaryotes (Murphy et al., 2013). Various phages have been shown to be able to mediate HGT of RM 
genes, indicating that phages are common vectors for these immune systems (Murphy et al., 2013). RM genes frequently co-localize with viral and TE sequences such as integrases and transposases and in some cases are flanked by inverted repeats and target site duplications, hallmarks of TEs (Naderer et al., 2002; Furuta et al., 2010; Makarova et al., 2011; Takahashi et al., 2011). TEs carrying functional RM systems have been identified (Khan et al., 2010), raising the possibility that these defense systems evolutionarily originate from TEs. Some restriction endonucleases can also trigger programmed cell death of bacteria (Nagamalleswari et al., 2017). This phenomenon of 'bacterial apoptosis' has been described as a mechanism that occurs upon phage infection to limit spread of the virus, reminiscent of eukaryotic apoptosis triggered by viral infection (Chopin et al., 2005).

A number of additional prokaryotic innate anti-phage systems have recently been identified (Koonin, 2018). These include prokaryotic Ago proteins that cleave invading DNA or RNA with RNase H-like nuclease domains (Swarts et al., 2014), BREX, which blocks phage replication and methylates bacterial DNA, enabling BREX to differentiate between host and phage genomes (Goldfarb et al., 2015) and DISARM, which also methylates host DNA and restricts invading dsDNA phages (Ofir et al., 2017). In addition, a number of defense systems were recently identified by a systematic search for genes clustering with defense islands, regions involved in defense processes that are widely abundant in prokaryotic genomes (Makarova et al., 2011; Doron et al., 2018). Ten of the novel defense systems were verified experimentally in vitro either in Escherichia coli or Bacillus subtilis that became resistant to a panel of phages upon introduction of the defense system. Interestingly, TE sequences are enriched in defense islands (Doron et al., 2018). The majority of prokaryotic TEs encode DDE superfamily transposases with an RNase $\mathrm{H}$ fold (named after two aspartate and one glutamate residue that form a catalytic triad) that mediate mobility via a cut-and-paste mechanism (Koonin and Krupovic, 2015). It remains unknown if these TEs serve a functional role, or whether their accumulation in defense island is simply less deleterious compared to other genomic loci. It is tempting to speculate, however, that some of the defense island-associated TE sequences, especially the RNase H-like transposases, may have been captured by the host to fulfill defense functions, or that they have contributed to the spread of immune systems.

\section{PROTECTION FROM RETROVIRAL INFECTION BY ENDOGENIZED enV GENES}

Eukaryotic genomes harbor large amounts of endogenous retrovirus (ERV) sequences, which are remnants of retroviral infections of ancestral germline cells. The human and mouse genomes, for instance, contain about $8 \%$ and $10 \%$ ERV sequences, respectively (Gifford and Tristem, 2003; Broecker et al., 2016). Among the best studied examples of retroviral genes that have been captured by mammalian (and some reptilian) hosts are the syncytins (Lavialle et al., 2013). Syncytins originate from env genes of endogenized proviruses. Full-length proviruses harbor the three retroviral genes, gag, pol and env, flanked by two LTRs. ERVs not subject to any selective pressure are inactivated by mutation to various degrees over time (Broecker et al., 2016). In rare occasions, however, certain proviral genes have been conserved over millions of years of evolution (Figure 2A), suggesting a selective advantage of that gene to the host. Retroviral env genes have been repeatedly captured from different proviruses at least 17 times during evolution and as syncytins or related genes exert critical physiological functions in the placental development of various mammalian and viviparous lizard species (Figure 2B) (Cornelis et al., 2017; Imakawa and Nakagawa, 2017).

Syncytins also likely contribute to maternal immune tolerance toward the fetus via the immunosuppressive domain (ISD) (Figure 2C). The ISD has been demonstrated to exert various immunosuppressive functions in vitro and in vivo, including an inhibition of the activity of lymphocytes, natural killer cells, monocytes and macrophages as well as the downregulation of pro-inflammatory cytokines (Cianciolo et al., 1985; Haraguchi et al., 1995, 1997, 2008). An env-derived syncytin gene has recently been identified in viviparous lizards that possess a mammalian-like placenta (Cornelis et al., 2017). Thus, syncytin capture is not restricted to mammals and likely a hallmark of placental evolution in general.

In addition to syncytins and related genes, other retroviral env genes have been captured for anti-retroviral functions. The first described example, the Friend virus susceptibility 4 (Fv4) gene, confers resistance to murine leukemia viruses (MuLVs) in mice (Suzuki, 1975). FV4 is a truncated MuLVrelated provirus containing the $3^{\prime}$ portion of pol, the entire env gene and the $3^{\prime}$ LTR (Ikeda et al., 1985). Binding of the env-encoded protein to the cellular receptor used by MuLV prevents infection by the exogenous retrovirus, a process termed receptor blockade. Another captured env gene in mice, resistance to MCF (Rmcf), mediates resistance to mink cell focus-inducing (MCF) viruses and MuLVs, likely also via receptor blockade (Hartley et al., 1983; Brightman et al., 1991; Jung et al., 2002).

Jaagsiekte sheep retrovirus (JSRV) co-exists both as exogenous and endogenous form (Armezzani et al., 2014). JSRV is an example of recent or ongoing endogenization, with the youngest identified endogenous elements (enJSRV) having integrated about 200 years ago. The sheep genome harbors at least 27 enJSRV sequences, 16 of which with intact env genes. enJSRV env is expressed in the ovine placenta and knockdown with antisense oligonucleotides has been shown to cause defects in trophoblast differentiation and pregnancy loss (Dunlap et al., 2006). This demonstrates that even recently endogenized, mostly intact env genes can exert syncytin-like functions. In addition, enJSRV env expression has been shown to block exogenous JSRV via receptor blockade (Spencer et al., 2003).

In cats, the refrex- 1 gene mediates resistance to feline leukemia virus-D (FeLV-D) (Ito et al., 2013). Refrex-1 is a truncated 

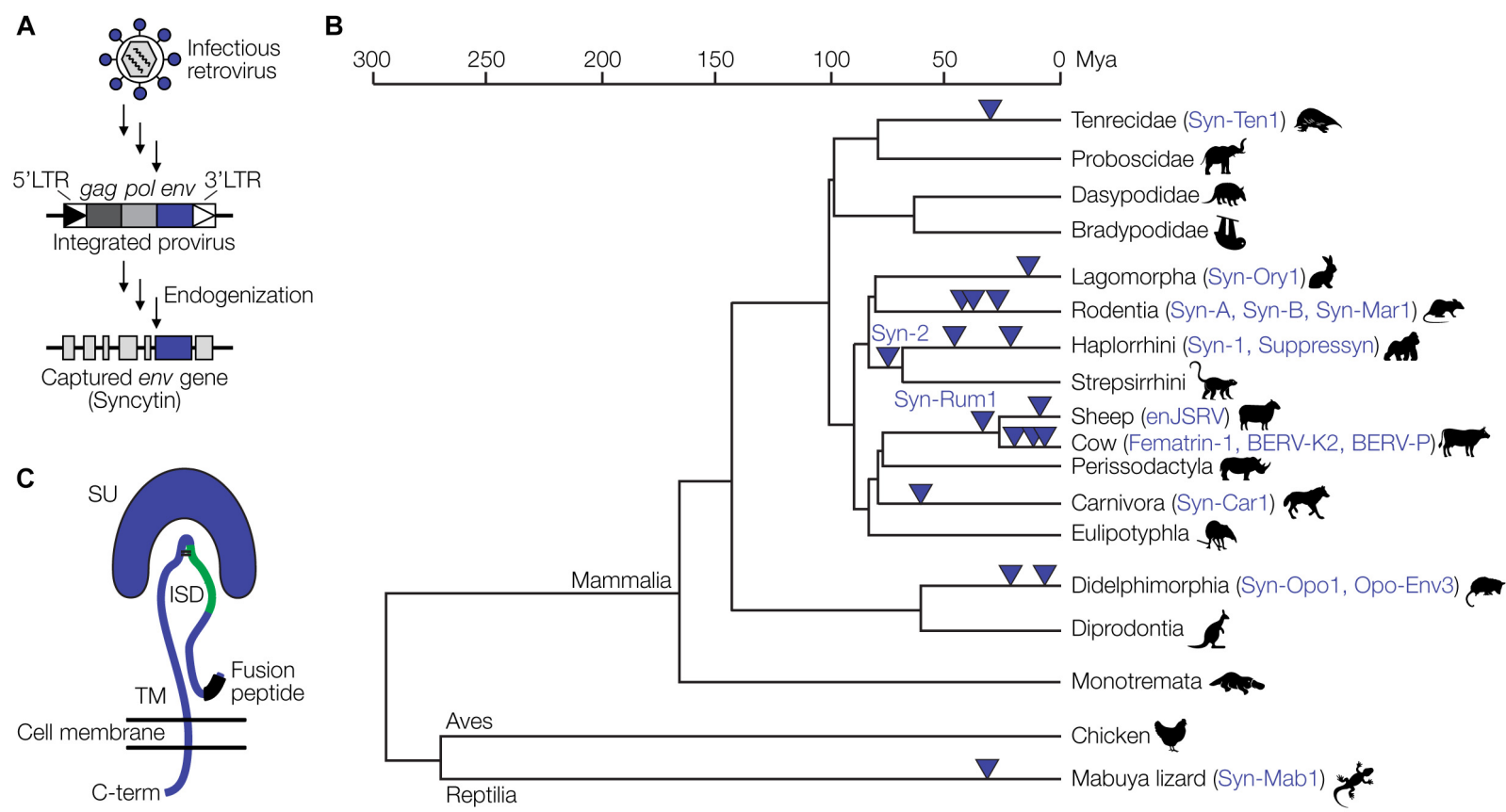

FIGURE 2 | Capture of retroviral genes for placental development. (A) Schematic of endogenization and capture of a syncytin gene. A retrovirus infecting a germline cell integrates into the host genome as a provirus with characteristic features, the $5^{\prime}$ LTR, gag, pol and env genes, and the $3^{\prime}$ LTR. Over time, in a process termed endogenization, most of the provirus acquires deleterious mutations. In this example, the env gene retains an intact open reading frame and is captured by the host to fulfill functions during placental development. (B) Evolution of placental species and capture of ERV-derived env genes. The phylogenetic tree is based on previously published data (Cornelis et al., 2017; Imakawa and Nakagawa, 2017). (C) Structural representation of the retroviral Env protein with the surface (SU), transmembrane (TM), and immunosuppressive domain (ISD) subunits, as well as the fusion peptide. Panel (C) has been modified from Lavialle et al. (2013).

retroviral env gene, such that the protein contains the signal peptide (SP) and the N-terminus of the surface unit (SU) that is a putative receptor-binding domain, but lacks the C-terminus of SU and the transmembrane (TM) domain due to a premature stop codon (Figure 2C).

In human cells, it has been recently shown that the Env protein encoded by a HERV-K(HML-2) provirus interferes with HIV-1 production in vitro through an unknown mechanism (Terry et al., 2017). The provirus, HERV-K108, encodes fulllength Env with four mutations compared to the consensus, ancestral HERV-K(HML-2) protein. These mutations appear to be required for inhibiting HIV-1. Interestingly, HERV-K(HML2) expression in $T$ cells is increased upon HIV-1 infection (Contreras-Galindo et al., 2007; Gonzalez-Hernandez et al., 2012). It is therefore tempting to speculate that inducible HERV-K(HML-2) proviruses have been evolutionarily conserved to express Env (and Gag, see below) to protect against exogenous retroviruses such as HIV. Another example of an evolutionarily conserved env gene with antiviral function in human cells is HERV-T env (Blanco-Melo et al., 2017). Expression of this gene mediates resistance to a reconstructed infectious HERV-T virus (the virus is extinct) by receptor blockade. Interestingly, the consensus env of the resurrected virus, but not the single endogenized env gene could be used by the virus for successful infection. This indicates that the env gene has been modified evolutionarily to bind to the viral receptor while losing its ability to constitute infectious virions. In addition, Suppressyn, a truncated env gene from a HERV-F element with a known role in placental development (see above), has been suggested to serve as restriction factor for exogenous retroviruses (Malfavon-Borja and Feschotte, 2015).

\section{PROTECTION FROM RETROVIRAL INFECTION BY ENDOGENIZED gag GENES}

Another retroviral gene that has been frequently captured by mammalian hosts is gag. The best studied gag-derived restriction factor is the mouse gene Friend virus susceptibility 1 (Fv1) (Best et al., 1996). Fv1 inhibits MuLV at a stage post-entry but before integration of the provirus, with the exact mechanism still unknown. The Fv1 protein has been shown to interact with the retroviral capsid protein (CA) in the preintegration complex of MuLV (Best et al., 1996). Fv1 originates from a MERV-L gag gene that has little sequence homology with that of MuLV, implying that Fv1 and its target share structural properties despite few sequence similarities. In sheep, enJSRV expressed Gag has been shown to inhibit virion formation of exogenous JSRV, however, in contrast to Fv1, at a late stage during viral assembly (Palmarini et al., 2004). In human cells, the HERV-K(HML-2) CA protein inhibits release of HIV-1 and 
reduces infectivity of progeny HIV-1 virions (Monde et al., 2017).

\section{OTHER ANTIVIRAL EFFECTS MEDIATED BY ENDOGENOUS RETROVIRUSES}

In addition to Env- and Gag-mediated restriction, more indirect mechanisms of antiviral protection by ERVs have been described. In human cells, the HERV-K Rec protein expressed during early embryogenesis activates innate immune responses by inducing expression of the IFITM1 gene, which protects the cell from viral infection (Grow et al., 2015). Moreover, ERVs have introduced and amplified interferon (IFN)-inducible enhancers within eukaryotic genomes and provide transcription factor binding sites (TFBS) that are enriched in proximity to genes involved in immune pathways (Chuong et al., 2016; Ito et al., 2017). This suggests that ERV sequences have been specifically adopted by host cells to modulate IFN responses, a major branch of the antiviral immune defense. An example in the human genome is the HERV-K(HML-10) family recently described by us and others (Broecker et al., 2016; Grandi et al., 2017). TFBS within the LTRs are frequently occupied, as determined by the ENCODE project (Davis et al., 2018), especially in the human myelogenous leukemia cell line K562 (Figure 3A). HERV$\mathrm{K}(\mathrm{HML}-10)$ elements appear to be enriched in loci involved in immunity such as the extended major histocompatibility complex (xMHC) and the extended leukocyte receptor complex (xLRC)

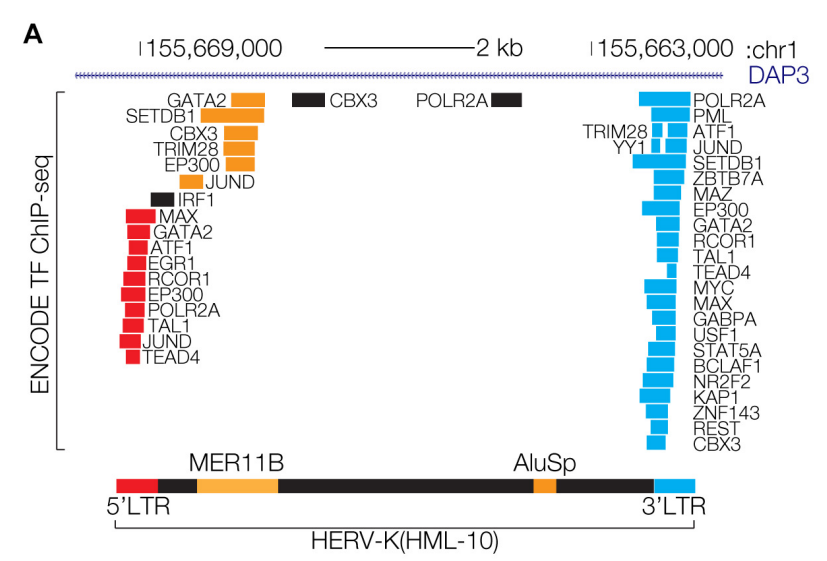

C
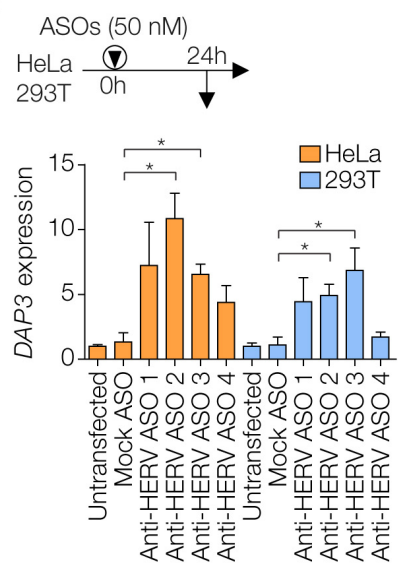

D $\mathrm{HeLa} \underset{\mathrm{Oh}}{\stackrel{(}{\text { Oh }}}$

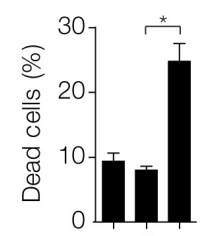

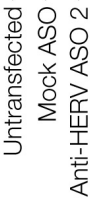

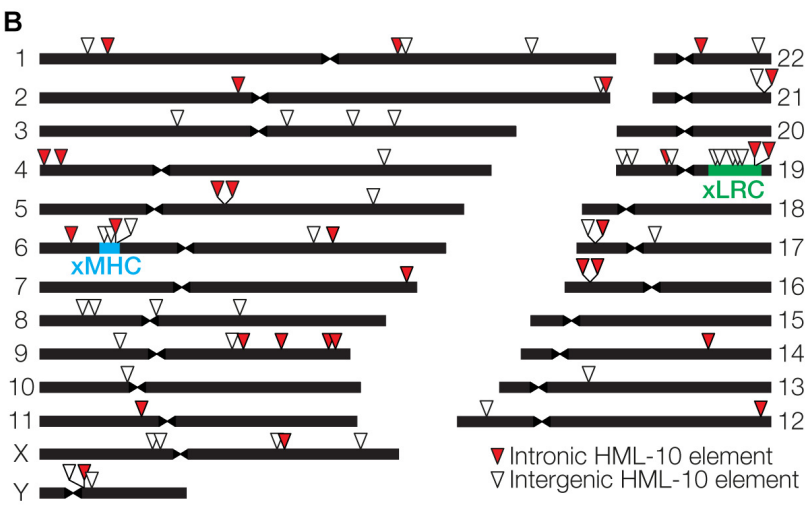

E

FIGURE 3 | Regulatory functions of HERV-K(HML-10) elements. (A) Genomic region of a HERV-K(HML-10) provirus in the first intron of the DAP3 gene. Repeat elements are according to RepeatMasker (Smit et al., 2013-2015) annotation. Two retroelements, MER11B and AluSp, are integrated into the provirus. Occupied transcription factor binding sites, as determined by ENCODE (Davis et al., 2018), are indicated and color-coded according to localization within the HERV-K(HML-10) provirus. Image modified from the UCSC Genome Browser (Kent et al., 2002) with the hg19 release of the human genome. (B) Chromosomal distribution of HERV-K(HML-10) elements in the human genome. The locations of the extended major histocompatibility complex (xMHC) and the extended leukocyte receptor complex (XLRC) are indicated. (C) Cells were transfected with indicated antisense oligonucleotides (ASOs). Anti-HERV ASOs target a HERV-K(HML-10) derived regulatory transcript, Mock ASO has an unrelated sequence. At $24 \mathrm{~h}$ after transfection, DAP3 mRNA expression levels were determined by qRT-PCR and normalized to GAPDH levels. Bars show mean \pm SEM of three experiments, untransfected cells were set to $1 .{ }^{*} P \leq 0.05$, Student's $t$-test against Mock. (D) HeLa cells were transfected with the indicated ASOs. After $48 \mathrm{~h}$, Trypan Blue exclusion as indicator of dead cells (left) and MTS cell viability assays (center) were performed. The right subpanel shows genomic DNA of these cells prepared with the Apoptotic DNA Ladder Kit (Roche) and analyzed on an ethidium bromide stained agarose gel. The positive control DNA is from apoptotic U937 cells provided with the kit. Bars show mean \pm SEM of three experiments in duplicates. ${ }^{*} P \leq 0.05$, Student's $t$-test. (E) Model of regulation of DAP3 expression by the HERV-K(HML-10) primed regulatory transcript. The approximate location of ASO 2 is indicated. This figure shows data modified from Broecker et al. (2016). 
(Barrow and Trowsdale, 2008; Horton et al., 2004) (Figure 3B). The data suggests that HML-10 has been captured by the host for the regulation of immune-related genes.

We have recently described a HERV-K(HML-10) provirus that regulates $D A P 3$ gene expression in vitro through an antisense mechanism, likely via a long non-coding RNA (Figure 3C) (Broecker et al., 2016). Inactivating the HERVderived RNA by antisense oligonucleotides was sufficient to induce apoptosis in vitro (Figure 3D), demonstrating that HERVmediated antisense regulation can directly influence the cellular phenotype (Figure 3E). In addition, there is evidence for HERVmediated gene regulation in humans in vivo. The complement component $\mathrm{C} 4$ gene in the xMHC exists in two variants, one with a transcriptionally active intron-located HERV-K(HML-10) provirus, and one without it (Schneider et al., 2001; Yang et al., 2003; Mack et al., 2004; Broecker et al., 2016). The presence of the provirus correlates with lower $\mathrm{C} 4$ protein serum concentrations, indicating that the HERV regulates $C 4$ expression, perhaps via an antisense mechanism (Yang et al., 2003). The fact that HERVderived RNA can regulate expression of cellular genes also suggests that HERV antisense transcripts arising from intronic proviruses could suppress mRNA of exogenous retroviruses. In support of this, HERV antisense transcripts arising from intronlocated proviruses have been shown to suppress complementary retroviral transcripts in trans (Schneider et al., 2001; Mack et al., 2004). Recombination between exogenous retroviruses and ERVs is another restriction mechanism, which may occur when defective ERV transcripts are co-packaged with the intact retroviral RNA into the same virion, or at the level of proviral DNA during meiosis (Löber et al., 2018).

\section{ENDOGENIZATION IN REAL TIME: KOALA RETROVIRUS}

An ongoing retroviral endogenization occurs in koalas. Koala retrovirus (KoRV) co-exists as both exogenous and endogenous form (Stoye, 2006; Tarlinton et al., 2006). High KoRV viral loads are associated with fatal lymphoid neoplasia. Since integration sites and copy numbers of proviruses are heterogeneous among individuals, and some koala populations isolated from mainland Australia since around the year 1900 are free of KoRV, the virus has likely entered the koala genome only about 100 years ago and is still undergoing endogenization. KoRV endogenization is possibly associated with resistance of koalas against the exogenous virus (Colson et al., 2015). To date it is unclear if Env or Gag-mediated restriction mechanisms may protect from exogenous KoRV. However, many endogenous proviruses have gag and env genes with complete open reading frames (ORFs), usually with point mutations (Oliveira et al., 2007). The mutated KoRV genes, when incorporated into retroviral vectors based on the closely related gibbon ape leukemia virus (GALV) that uses the same entry receptor as KoRV substantially reduced infectivity compared to the GALV gag and env genes. This suggests that KoRV endogenization is associated with mutations that render the proviruses incapable of producing highly infectious viruses. Yet, preservation of intact gag and env ORFs may indicate a functional importance, perhaps as restriction factors against exogenous KoRV. Moreover, some koala populations such as those located in Southern Australia (SA) are relatively resistant to KoRV induced disease and usually have low viral loads (Tarlinton et al., 2017). In contrast, koalas in northern Australia such as Queensland suffer from higher viremia and disease burden, and active KoRV infection is more prevalent. Of note, both populations have endogenous KoRV proviruses which, however, differ in their RNA expression patterns. While koalas from Queensland express mainly full-length proviruses, including the complete gag, pol and env genes, koalas from SA preferentially express the $5^{\prime}$ portion of gag and the $3^{\prime}$ portion of env, whereas pol transcripts are weak or undetectable. This may reflect ongoing endogenization events in which short variants of Gag and Env are preserved that mediate restriction to exogenous KoRV. Of note, the Fv1 restriction factor in mice is also not a full-length Gag protein but covers the first three-fourth of the retroviral Gag protein it is likely derived from (Bénit et al., 1997). Another explanation for why koalas from Queensland are not protected from KoRV is that expression of the full-length KoRV genes tolerizes the animals to the virus in utero, rendering their immune systems unable to recognize and respond to the exogenous virus. This may explain why many animals from Queensland do not have antibodies to KoRV and also do not elicit them upon vaccination (Fiebig et al., 2015; Waugh et al., 2016).

\section{HIV EN ROUTE TO ENDOGENIZATION?}

Is HIV currently ongoing endogenization in humans? HIV is a complex retrovirus of the lentivirus genus. In contrast, ERVs are typically derived from simple retroviruses. The first endogenous lentivirus, RELIK (rabbit endogenous lentivirus-K) was identified only in 2007 (Katzourakis et al., 2007) [simple ERVs have been known since the 1960s (Weiss, 2006)], followed by the reports of several endogenous lentiviruses in primate (Gifford et al., 2008; Gilbert et al., 2009; Han and Worobey, 2015), ferret (Cui and Holmes, 2012), and weasel genomes (Han and Worobey, 2012). Still, the vast majority of known ERVs are derived from simple retroviruses, suggesting that endogenization of lentiviruses has been a relatively rare event, perhaps due to the recent evolutionary origin of lentiviruses (Katzourakis et al., 2007).

A prerequisite for endogenization to occur is the capability of a retrovirus to infect germline cells. Whether HIV can infect human germline cells is controversial. HIV-1 particles have been detected on the cell membrane and inside in vitro infected spermatozoa (Baccetti et al., 1994, 1998; Barboza et al., 2004; Cardona-Maya et al., 2009). In addition, HIV-1 proviral DNA has been detected by PCR in spermatozoa of HIV-1 infected individuals (Bagasra et al., 1994; Nuovo et al., 1994; CardonaMaya et al., 2009). HIV-1 particles can associate with spermatozoa by binding to mannose receptor, which can transfer the virus into oocytes (Baccetti et al., 1994; Cardona-Maya et al., 2011). These findings indicate that sperm cells can be infected and subject to provirus integration, and can also act as vectors of HIV-1 virions to infect oocytes. Therefore, endogenization of HIV-1 appears 
to be possible in theory. Vertical transmission of proviral DNA through the germline, however, has not been demonstrated yet.

A recently reported HIV-1 patient controlling the infection without antiretroviral therapy despite not having the CCR5- $\Delta 32$ mutation or a protective HLA genotype suggests that the presence of HIV-1 proviruses in lymphocytes may protect against AIDS (Colson et al., 2014). PBMCs from this patient harbored defective HIV-1 proviruses and could not be superinfected with the same strain of HIV-1 in vitro, suggesting that the proviruses rendered the PBMCs resistant to infection. The proviruses harbored a number of premature stop codons likely introduced by the APOBEC3G restriction factor, however, some ORF were intact. The presence of apparently protective HIV-1 proviruses suggests that SIEx mediated by HIV-1 proviruses is likely possible. Thus, a potential germline infection with HIV-1 may confer inheritable resistance against HIV-1 induced disease.

\section{PROTECTION AGAINST VIRAL INFECTION BY ENDOGENIZED NON-RETROVIRAL GENES IN EUKARYOTES}

Mammalian genomes not only contain ERVs and TEs, but also a number of sequences derived from Bornaviridae, Filoviridae, Parvoviridae, Circoviridae, Rhabdoviridae, and others (Belyi et al., 2010a,b; Horie et al., 2010; Katzourakis and Gifford, 2010; Aswad and Katzourakis, 2014). Genomic sequences from RNA viruses without an RT are likely processed pseudogenes originating from illegitimate reverse transcription and integration by the replication machinery of long interspersed nuclear elements (LINEs), or they have arisen from recombination with ERV RNA (Suzuki et al., 2014).

The best studied example of the function of non-retroviral endogenous virus sequences are Borna disease viruses (BDVs). BDVs are neurotropic negative sense ssRNA viruses causing fatal encephalitis (Borna disease) in horses, sheep and cattle (Carbone, 2001; Belyi et al., 2010b). These highly susceptible species have no detectable endogenous BDV sequences in their genomes (Belyi et al., 2010b). BDV also persistently infects other species, from avian to primate, and in experimental animals such as mice can induce behavioral changes without obvious signs of encephalitis. Interestingly, the genomes of primates, rats, and mice and squirrels, which are relatively resistant to the virus, harbor BDV sequences (Belyi et al., 2010b). This suggests a protective role of endogenous $\mathrm{BDV}$ sequences in protecting against disease caused by exogenous BDV.

Experimental evidence for protection mediated by endogenous BDV sequences has been obtained in squirrels. The genome of the 13-lined ground squirrel Ictidomys tridecemlineatus contains an endogenous bornavirus-like nucleoprotein (itEBLN) sequence that shares $77 \%$ amino acid similarity with current infectious BDV (Fujino et al., 2014). itEBLN colocalizes with the viral factory of BDV in the nucleus and suppresses viral replication and cell-to-cell spread in vitro, likely acting as a dominant negative nucleoprotein that is incorporated into BDV virions, which renders them noninfectious. Thus, itEBLN may serve as immune memory against exogenous BDV.

Like squirrels, humans usually do not experience Borna disease, with only three cases of fatal BDV-induced viral encephalitis reported to date resulting from zoonotic infections from squirrels (Hoffmann et al., 2015) and three more cases (two of which fatal) of human-to-human transmission during organ transplantation (Friedrich-Loeffler-Institut, 2018). All of the seven human endogenous bornavirus-like nucleoprotein elements (hsEBLN-1 through hsEBLN-7) are expressed as RNA in one or more tissues (Sofuku et al., 2015). At least one of them, hsEBLN-2, is also expressed as protein in human cells (Ewing et al., 2007). In primates and rodents, EBLNs are significantly enriched in piRNA clusters (Parrish et al., 2015). Three of the seven hsEBLN genes and three of five rodent EBLNs are located in piRNA clusters. Interestingly, piRNA cluster-located EBLNs in both rodents and primates produce bona fide piRNAs, which are antisense relative to the BDV nucleoprotein mRNA and are expressed in the testes. Whether piRNA-mediated inhibition of BDV infection occurs in germline cells, however, remains to be determined. As piRNAs can also be expressed in somatic cells including neurons (Lee et al., 2011), EBLN sequences may also protect from BDV infection in the brain, which may at least partially explain the resistance of species with endogenous EBLN sequences to viral encephalitis. Another potential mechanism by which EBLNs may protect from Borna disease is the induction of immune tolerance by in utero expression of EBLN protein (Horie, 2017). Tolerization of the adaptive immune system to the EBLN protein in utero may limit the immune response to the nucleoprotein during BDV infection. The BDV nucleoprotein is known as a major target for cytotoxic $\mathrm{T}$ cell responses (Planz and Stitz, 1999). In utero tolerization to this antigen may be protective, as most of the symptoms of fatal $\mathrm{BDV}$ infection arise from immune-mediated inflammation. A further antiviral mechanism might occur at the RNA level. EBLN RNAs could act as antisense transcripts to the genomic minus sense ssRNA genome of BDV that replicates in the nucleus (Horie, 2017). Aside from squirrels, primates and rodents, EBLN sequences have been identified in Afrotherians, bats, whales, birds, and lamprey (Kobayashi et al., 2016; Hyndman et al., 2018). It is conceivable that some of these elements also exert anti-viral functions.

The genomes of Aedes mosquitoes which are important vectors for human pathogenic flaviviruses such as Dengue and Zika contain various endogenous flaviviral sequences (Suzuki et al., 2017). piRNAs and siRNAs are produced from these endogenous viruses and might play a role in antiviral defense. It is known that small RNAs play an important role in antiviral defense in insects (Cullen et al., 2013).

A variation of SIEx can also be mediated by viruses that infect other viruses, termed virophages. The protozoan Cafeteria roenbergensis is infected by Cafeteria roenbergensis virus (CroV), a giant virus that causes lysis of the host (Fischer and Suttle, 2011). CroV is infected by the virophage Mavirus (Fischer and Hackl, 2016). C. roenbergensis cells co-infected with $\mathrm{CroV}$ and Mavirus are protected from lysis, as Mavirus inhibits 
replication of CroV. Interestingly, Mavirus can integrate into the genome of $C$. roenbergensis where it stays inactive until the cell is infected with CroV. The activated Mavirus then inhibits CroV replication, thus providing an adaptive, inducible immunity of $C$. roenbergensis against detrimental CroV infection. Stably integrated into the $C$. roenbergensis genome, Mavirus is passed on to the next generation of the protozoan, which can be regarded as a simple form of an inheritable immune system.

Polintons, TEs related to virophages, are found in the genomes of diverse eukaryotic species and likely originate from viruses with an exogenous form (Koonin and Krupovic, 2018). They may represent endogenized virophages that, unlike Mavirus in C. roenbergensis, have lost the ability to form virions. Polintons may have been recruited by their eukaryotic hosts as a defense against past or present viruses, whose identity remains to be determined.

\section{ADAPTIVE IMMUNITY OF JAWED VERTEBRATES: V(D)J RECOMBINATION}

In contrast to the adaptive immune system of prokaryotes, CRISPR-Cas, immunological memory in vertebrates is restricted to somatic cells and is therefore not inherited to the next generation. In jawed vertebrates, the diversity of immunoglobulins/antibodies and TCRs is generated by $V(D) J$ recombination, in which variable $(\mathrm{V})$, diversity (D) and joining (J) segments are recombined. Further antibody diversification is then achieved by somatic hypermutation (Kapitonov and Koonin, 2015).

The ability to produce diversity of antibodies and TCRs in jawed vertebrates developed at around 500 mya (Kapitonov and Koonin, 2015). Both the Rag1 and Rag2 proteins required for $\mathrm{V}(\mathrm{D}) \mathrm{J}$ recombination are found in one genomic locus and originate from a Transib transposon that today is found in the genomes of starfish, oysters and sea urchins, but not anymore in those of jawed vertebrates (Kapitonov and Koonin, 2015). Rag1 is the nuclease responsible for $\mathrm{V}(\mathrm{D}) \mathrm{J}$ recombination, which contains an RNase H-like domain with the conserved DDE catalytic triad.

\section{POSSIBLE EVOLUTION OF COMPONENTS OF RNA INTERFERENCE FROM VIRUSES}

The retroviral replication machinery and Argonaute (Ago)mediated interference pathways against invading nucleic acids share some surprising similarities at the structural and functional level (Moelling et al., 2006a, 2017; Moelling and Broecker, 2015). At the core of retroviral replication is the reverse transcriptaseRNase $\mathrm{H}$ (RT-RNase $\mathrm{H}$ ) that resembles Ago proteins consisting of PAZ (N-terminal), MID (central) and PIWI (C-terminal) domains (Figure 4A). The C-terminal domains of both proteins adopt an RNase $\mathrm{H}$-fold, one of the most ancient and abundant protein folds found in nature (Figures 4B,C) (Wang et al., 2006;
Ma et al., 2008; Majorek et al., 2014). These domains have nuclease activity and cleave the target RNA/DNA (the template retroviral RNA during retroviral replication or the nucleic acid targeted by Ago via the guide nucleic acid) (Mölling et al., 1971; Song et al., 2004). The N-terminal domains of both proteins, RT of the RT-RNase $\mathrm{H}$ and PAZ of Ago, among other functions, serve as nucleic acid binding modules that direct the cleavage specificity of the RNase $\mathrm{H}$ domains. The RNA/DNA binding activity in the RT domain of RT-RNase $\mathrm{H}$ is located in conserved residues binding the template RNA strand ("template grip") as well as the opposite cDNA strand ("primer grip") (Dash et al., 2008). In the case of Ago, the PAZ domain is an oligonucleotidebinding domain that interacts with the $3^{\prime}$ end of the guide (Song et al., 2004). Further interactions with the $5^{\prime}$ end of the guide are made by the MID domain (Lima et al., 2009). In both RTRNase $\mathrm{H}$ and Ago, the N-terminal domains fused to the RNase $\mathrm{H}$ domain determine the specificity of the nuclease activity. The widespread presence of Ago proteins in prokaryotes and eukaryotes with conserved structures and functions suggests an ancient evolutionary origin, possibly before the last eukaryotic common ancestor (Swarts et al., 2014). The diverse Ago proteins can act as RNA- or DNA-guided nucleases and can cleave RNA or DNA through the RNase H-like PIWI domain. In both prokaryotes and eukaryotes, Ago-centered defense can be regarded as a mechanism of innate immunity (Koonin and Krupovic, 2015).

RNAi is triggered by siRNAs, short (21-24 nucleotides) double-stranded RNAs with two nucleotide overhangs at the $3^{\prime}$ ends, which are produced by Dicer from longer dsRNA molecules. A DNA molecule structurally related to siRNAs, a partially double-stranded hairpin-loop 54-mer oligodeoxynucleotide (ODN) is an efficient inducer of the HIV-1 RT-RNase H, leading to cleavage of the retroviral RNA genome (Moelling et al., 2006b). Interestingly, the human AGO2 protein can use both siRNAs and ODNs to find and cleave target RNA in a sequence-specific manner in vitro - albeit with lower efficiency with the ODN (Moelling et al., 2006a). Vice versa, siRNAs are recognized by the HIV-1 RT-RNase H to induce target RNA cleavage but with lower efficiency than the corresponding ODN. These common activities suggest an evolutionary relationship between the RT-RNase H and AGO2. Another component required for RNAi, the RNA-dependent RNA polymerase (RdRP) that amplifies siRNAs, likely originated from a phage (Shabalina and Koonin, 2008). The RdRP was likely present in the last eukaryotic common ancestor and is still active in plants and nematodes (Shabalina and Koonin, 2008).

While eukaryotic Ago proteins are generally believed to only use RNA as guides, prokaryotic Ago proteins have been demonstrated previously to also accept DNA as guides, with important functions in vivo (Yuan et al., 2005). The abovementioned activity of AGO2 with a DNA guide against HIV-1 RNA in the test tube suggests that mammalian RNAi may also be triggered by DNA guides to serve biological functions. Indeed, DNA molecules have been shown to bind to the PAZ domain of AGO2 and localize into mRNA-degrading $\mathrm{P}$ bodies, hallmark features of RNAi-mediated degradation (Castanotto 

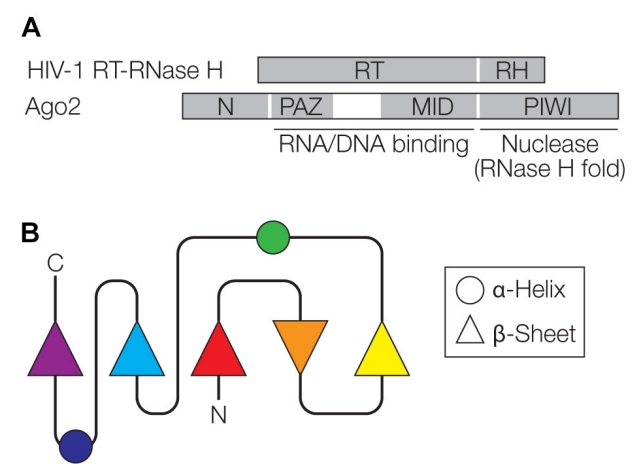

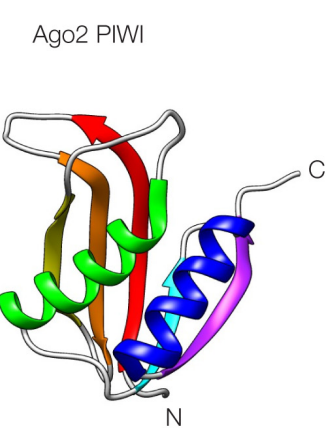

FIGURE 4 | Similarities between retroviral reverse-transcriptase (RT)-RNase H and Argonaute. (A) Domain organization of the HIV-1 RT-RNase H and Argonaute 2 (Ago2) from Pyrococcus furiosus. The RT domain of RT-RNase $\mathrm{H}$ and the Piwi Argonaute Zwille (PAZ) and middle (MID) domains of Ago2 contain regions involved in nucleic acid binding. The RNase $\mathrm{H}(\mathrm{RH})$ and PIWI domains adopt an RNase $\mathrm{H}$ fold and serve as nucleases. (B) Schematic of the RNase $\mathrm{H}$ fold. (C) The RNase $\mathrm{H}$ and PIWI domains are shown next to each other, with $\alpha$-helices and $\beta$-sheets color-coded as in panel (B). PDB accession numbers are 2 I5J for the RNase $H$ (Himmel et al., 2006) and 1 U04 for Ago2 (Song et al., 2004) The gray helix in the HIV structure is an additional helix not shown in (B). Structures were visualized with UCSF Chimera (Pettersen et al., 2004).

et al., 2015). It has been suggested that cytosolic genomic DNA (cgDNA) functions as natural antisense mechanism triggering RNA degradation, perhaps involving AGO2 (Asada et al., 2018). Single-stranded cgDNA of TE origin can be detected in mammalian cell lines and may act as a natural antisense mechanism against the RNA of retrotransposons, especially ERVs (Stetson et al., 2008; Asada et al., 2018). However, under normal conditions in vivo the exonuclease TREX1 appears to degrade single-stranded cgDNA, preventing the antisense inhibition. Notably, loss of function mutations in the human TREX1 gene cause Aicardi-Goutières Syndrome (Crow et al., 2006), an autoimmune disease characterized by the accumulation of cytosolic ssDNA (Yang et al., 2007), including ssDNA of TEs, especially of ERV origin (Stetson et al., 2008). Thus, cgDNA may restrict TE transcripts via RNAi under conditions without or with low TREX1 expression.

Another mechanism by which TE-derived nucleic acids lead to inhibition of TE expression is the endogenous siRNA (endosiRNA) pathway (Ghildiyal et al., 2008; Nandi et al., 2016; Berrens et al., 2017). In this pathway, TE senseantisense RNA pairs that arise, for instance, from intronlocated TEs (Figure 1) are subject to RNAi, involving Dicer and AGO2, which suppresses TE activity in the mammalian germline (Berrens et al., 2017), the mammalian brain (Nandi et al., 2016) as well in somatic cells of Drosophila (Ghildiyal et al., 2008). It appears possible that a similar siRNA-based mechanism may also act against exogenous retroviral RNA if there is sufficient complementarity between an antisensetranscribed ERV and the mRNA of the exogenous retrovirus (Figure 1). Indeed, mammalian RNAi has been demonstrated in vitro to also act against exogenous viruses. This includes RNAi-mediated restriction of enteroviruses (Qiu et al., 2017), encephalomyocarditis virus and Nodamura virus (Maillard et al., 2013), Influenza virus (Matskevich and Moelling, 2007; Li et al., 2016), reovirus and Sindbis virus (Maillard et al., 2016). The biological relevance of siRNA in mammalian cells, however, is subject to debate, as many mammalian viruses efficiently counteract RNAi (tenOever, 2017; Tsai et al., 2018). Moreover, mammalian antiviral RNAi is usually only detected in cells defective in IFN signaling and may be restricted to embryonic stem cells. In plants, nematodes and invertebrates, however, RNAi plays an important role in antiviral defense (Cullen et al., 2013).

\section{CONCLUSION}

Recruitment of sequences from viruses, TEs, and other MGEs for immune defense mechanisms in prokaryotes and eukaryotes is strikingly common. Nucleases are involved in many immune systems, either to cleave invading DNA or to mediate genome editing events (Figure 1). Many of these are RNase H-like nucleases, including Ago/Piwi proteins involved in foreign nucleic acid cleavage in prokaryotes and in RNAi in eukaryotes, some CRISPR-Cas effector nucleases (Cas9 and Cas12), and the Rag1 protein that mediates $\mathrm{V}(\mathrm{D}) \mathrm{J}$ recombination. Thus, RNase H-like molecules are involved in different prokaryotic and eukaryotic immune systems of various origin. The fact that genomes of almost all cellular organisms harbor large numbers of MGEs suggests that yet unknown functionalities may be identified in the future. The recent discovery that defense islands in bacterial genomes are enriched with sequences of TEs further pinpoints their important role in immune defense mechanisms in prokaryotes. Their potential functions remain to be elucidated. In eukaryotes whose genomes usually contain even more TE sequences than prokaryotic ones, additional immune functions are also expected to be discovered. This includes TE-derived conserved genes such as HARBI1, which is conserved across vertebrates and originated from a Harbinger transposase, with yet unknown functions (Koonin and Krupovic, 2015).

It has to be noted that antiviral defense is by far not the only function of endogenized viruses and TEs. For example, deletion of all replication-deficient prophages in E. coli has resulted in 
fitness deficits under diverse environmental conditions, including increased susceptibility to antibiotics and osmotic stress, slower cell growth and reduced biofilm formation (Wang et al., 2010). In eukaryotes, TEs and ERVs do not only modulate IFN response genes and constitute antiviral defense mechanisms, but also play distinct roles in cell differentiation, stem cell pluripotency and embryonic development, amongst others (Chuong et al., 2017), and the industrial melanism mutation of peppered moths has been shown to be caused by a TE insertion (Van't Hof et al., 2016). These examples highlight the multifaceted roles of TEs and viral sequences in pro- and eukaryotes. However, given their diverse roles in various immune systems (Figure 1), it appears that recruitment of TEs, viral sequences and other MGEs for antiviral defense mechanisms has been a major driving force in the evolution of cellular life.

\section{REFERENCES}

Armezzani, A., Varela, M., Spencer, T. E., Palmarini, M., and Arnaud, F. (2014). "Ménage à Trois": the evolutionary interplay between JSRV, enJSRVs and domestic sheep. Viruses 6, 4926-4945. doi: 10.3390/v6124926

Asada, K., Ito, K., Yui, D., Tagaya, H., and Yokota, T. (2018). Cytosolic genomic DNA functions as a natural antisense. Sci. Rep. 8:8551. doi: 10.1038/s41598018-26487-1

Aswad, A., and Katzourakis, A. (2014). The first endogenous herpesvirus, identified in the tarsier genome, and novel sequences from primate rhadinoviruses and lymphocryptoviruses. PLoS Genet. 10:e1004332. doi: 10.1371/journal.pgen. 1004332

Baccetti, B., Benedetto, A., Burrini, A. G., Collodel, G., Ceccarini, E. C., Crisà, N., et al. (1994). HIV-particles in spermatozoa of patients with AIDS and their transfer into the oocyte. J. Cell Biol. 127, 903-914. doi: 10.1083/jcb.127. 4.903

Baccetti, B., Benedetto, A., Collodel, G., di Caro, A., Garbuglia, A. R., and Piomboni, P. (1998). The debate on the presence of HIV-1 in human gametes. J. Reprod. Immunol. 41, 41-67. doi: 10.1016/S0165-0378(98) 00048-5

Bagasra, O., Farzadegan, H., Seshamma, T., Oakes, J. W., Saah, A., and Pomerantz, R. J. (1994). Detection of HIV-1 proviral DNA in sperm from HIV-1-infected men. AIDS 8, 1669-1674. doi: 10.1097/00002030-19941200000005

Barboza, J. M., Medina, H., Doria, M., Rivero, L., Hernandez, L., and Joshi, N. Y. (2004). Use of atomic force microscopy to reveal sperm ultrastructure in HIV-patients on highly active antiretroviral therapy. Arch. Androl. 50, 121-129.

Barrow, A. D., and Trowsdale, J. (2008). The extended human leukocyte receptor complex: diverse ways of modulating immune responses. Immunol. Rev. 224, 98-123. doi: 10.1111/j.1600-065X.2008.00653.x

Belyi, V. A., Levine, A. J., and Skalka, A. M. (2010a). Sequences from ancestral single-stranded DNA viruses in vertebrate genomes: the parvoviridae and circoviridae are more than 40 to 50 million years old. J. Virol. 84, 12458-12462. doi: 10.1128/JVI.01789-10

Belyi, V. A., Levine, A. J., and Skalka, A. M. (2010b). Unexpected inheritance: multiple integrations of ancient bornavirus and ebolavirus/marburgvirus sequences in vertebrate genomes. PLoS Pathog. 6:e1001030. doi: 10.1371/ journal.ppat.1001030

Bénit, L., De Parseval, N., Casella, J. F., Callebaut, I., Cordonnier, A., and Heidmann, T. (1997). Cloning of a new murine endogenous retrovirus, MuERV-L, with strong similarity to the human HERV-L element and with a gag coding sequence closely related to the Fv1 restriction gene. J. Virol. 71, 5652-5657.

Berrens, R. V., Andrews, S., Spensberger, D., Santos, F., Dean, W., Gould, P., et al. (2017). An endosiRNA-based repression mechanism counteracts transposon activation during global DNA demethylation in

\section{AUTHOR CONTRIBUTIONS}

Both authors have written the manuscript and approved its final version.

\section{FUNDING}

FB was financially supported by a fellowship of the German Academy of Sciences Leopoldina.

\section{ACKNOWLEDGMENTS}

We would like to thank Prof. Peter Palese for his generous support.

embryonic stem cells. Cell Stem Cell 21, 694-703. doi: 10.1016/j.stem.2017. 10.004

Best, S., Le Tissier, P., Towers, G., and Stoye, J. P. (1996). Positional cloning of the mouse retrovirus restriction gene Fv1. Nature 382, 826-829. doi: 10.1038/ $382826 \mathrm{a} 0$

Blanco-Melo, D., Gifford, R. J., and Bieniasz, P. D. (2017). Co-option of an endogenous retrovirus envelope for host defense in hominid ancestors. eLife 6:e22519. doi: 10.7554/eLife.22519

Bondy-Denomy, J., and Davidson, A. R. (2014). When a virus is not a parasite: the beneficial effects of prophages on bacterial fitness. J. Microbiol. 52, 235-242. doi: $10.1007 /$ s12275-014-4083-3

Bondy-Denomy, J., Qian, J., Westra, E. R., Buckling, A., Guttman, D. S., Davidson, A. R., et al. (2016). Prophages mediate defense against phage infection through diverse mechanisms. ISME J. 10, 2854-2866. doi: 10.1038/ismej. 2016.79

Brightman, B. K., Li, Q. X., Trepp, D. J., and Fan, H. (1991). Differential disease restriction of Moloney and Friend murine leukemia viruses by the mouse Rmcf gene is governed by the viral long terminal repeat. J. Exp. Med. 174, 389-396. doi: 10.1084 /jem.174.2.389

Broecker, F., Horton, R., Heinrich, J., Franz, A., Schweiger, M. R., Lehrach, H., et al. (2016). The intron-enriched HERV-K(HML-10) family suppresses apoptosis, an indicator of malignant transformation. Mob. DNA 7:25. doi: 10.1186/s13100016-0081-9

Carbone, K. M. (2001). Borna disease virus and human disease. Clin. Microbiol. Rev. 14, 513-527. doi: 10.1128/CMR.14.3.513-527.2001

Cardona-Maya, W., Velilla, P., Montoya, C. J., Cadavid, A., and Rugeles, M. T. (2009). Presence of HIV-1 DNA in spermatozoa from HIV-positive patients: changes in the semen parameters. Curr. HIV Res. 7, 418-424. doi: 10.2174/ 157016209788680570

Cardona-Maya, W., Velilla, P. A., Montoya, C. J., Cadavid, Á., and Rugeles, M. T. (2011). In vitro human immunodeficiency virus and sperm cell interaction mediated by the mannose receptor. J. Reprod. Immunol. 92, 1-7. doi: 10.1016/j. jri.2011.09.002

Castanotto, D., Lin, M., Kowolik, C., Wang, L., Ren, X. Q., Soifer, H. S., et al. (2015). A cytoplasmic pathway for gapmer antisense oligonucleotide-mediated gene silencing in mammalian cells. Nucleic Acids Res. 43, 9350-9361. doi: 10.1093/ nar/gkv964

Chopin, M. C., Chopin, A., and Bidnenko, E. (2005). Phage abortive infection in lactococci: variations on a theme. Curr. Opin. Microbiol. 8, 473-479. doi: 10.1016/j.mib.2005.06.006

Chung, I. Y., Jang, H. J., Bae, H. W., and Cho, Y. H. (2014). A phage protein that inhibits the bacterial ATPase required for type IV pilus assembly. Proc. Natl. Acad. Sci. U.S.A. 111, 11503-11508. doi: 10.1073/pnas.140353 7111

Chuong, E. B., Elde, N. C., and Feschotte, C. (2016). Regulatory evolution of innate immunity through co-option of endogenous retroviruses. Science 351, 1083-1087. doi: 10.1126/science.aad5497 
Chuong, E. B., Elde, N. C., and Feschotte, C. (2017). Regulatory activities of transposable elements: from conflicts to benefits. Nat. Rev. Genet. 18, 71-86. doi: 10.1038/nrg.2016.139

Cianciolo, G. J., Copeland, T. D., Oroszlan, S., and Snyderman, R. (1985). Inhibition of lymphocyte proliferation by a synthetic peptide homologous to retroviral envelope proteins. Science 230, 453-455. doi: 10.1126/science. 2996136

Colson, P., Levy, Y., and Raoult, D. (2015). Response to a letter to the editor by Joachim Denner on HIV infection en route to endogenization: two cases. Clin. Microbiol. Infect. 21, e35-e37. doi: 10.1016/j.cmi.2014.11.029

Colson, P., Ravaux, I., Tamalet, C., Glazunova, O., Baptiste, E., Chabriere, E., et al. (2014). HIV infection en route to endogenization: two cases. Clin. Microbiol. Infect. 20, 1280-1288. doi: 10.1111/1469-0691.12807

Contreras-Galindo, R., López, P., Vélez, R., and Yamamura, Y. (2007). HIV-1 infection increases the expression of human endogenous retroviruses type $\mathrm{K}$ (HERV-K) in vitro. AIDS Res. Hum. Retrovi. 23, 116-122. doi: 10.1089/aid.2006. 0117

Cornelis, G., Funk, M., Vernochet, C., Leal, F., Tarazona, O. A., Meurice, G., et al. (2017). An endogenous retroviral envelope syncytin and its cognate receptor identified in the viviparous placental Mabuya lizard. Proc. Natl. Acad. Sci. U.S.A. 114, E10991-E11000. doi: 10.1073/pnas.1714590114

Crow, Y. J., Leitch, A., Hayward, B. E., Garner, A., Parmar, R., Griffith, E., et al. (2006). Mutations in genes encoding ribonuclease H2 subunits cause AicardiGoutières syndrome and mimic congenital viral brain infection. Nat. Genet. 38, 910-916. doi: 10.1038/ng1842

Cui, J., and Holmes, E. C. (2012). Endogenous lentiviruses in the ferret genome. J. Virol. 86, 3383-3385. doi: 10.1128/JVI.06652-11

Cullen, B. R., Cherry, S., and tenOever, B. R. (2013). Is RNA interference a physiologically relevant innate antiviral immune response in mammals? Cell Host Microbe 14, 374-378. doi: 10.1016/j.chom.2013.09.011

Dash, C., Scarth, B. J., Badorrek, C., Götte, M., and Le Grice, S. F. (2008). Examining the ribonuclease $\mathrm{H}$ primer grip of HIV-1 reverse transcriptase by charge neutralization of RNA/DNA hybrids. Nucleic Acids Res. 36, 6363-6371. doi: 10.1093/nar/gkn678

Davis, C. A., Hitz, B. C., Sloan, C. A., Chan, E. T., Davidson, J. M., Gabdank, I., et al. (2018). The encyclopedia of DNA elements (ENCODE): data portal update. Nucleic Acids Res. 46, D794-D801. doi: 10.1093/nar/gkx1081

Diener, T. O. (1989). Circular RNAs: relics of precellular evolution? Proc. Natl. Acad. Sci. U.S.A. 86, 9370-9374. doi: 10.1073/pnas.86.23.9370

Doron, S., Melamed, S., Ofir, G., Leavitt, A., Lopatina, A., Keren, M., et al. (2018). Systematic discovery of antiphage defense systems in the microbial pangenome. Science 359:eaar4120. doi: 10.1126/science.aar4120

Dunlap, K. A., Palmarini, M., Varela, M., Burghardt, R. C., Hayashi, K., Farmer, J. L., et al. (2006). Endogenous retroviruses regulate periimplantation placental growth and differentiation. Proc. Natl. Acad. Sci. U.S.A. 103, 14390-14395. doi: $10.1073 /$ pnas.0603836103

Ewing, R. M., Chu, P., Elisma, F., Li, H., Taylor, P., Climie, S., et al. (2007). Largescale mapping of human protein-protein interactions by mass spectrometry. Mol. Syst. Biol. 3:89. doi: 10.1038/msb4100134

Fiebig, U., Keller, M., Möller, A., Timms, P., and Denner, J. (2015). Lack of antiviral antibody response in koalas infected with koala retroviruses (KoRV). Virus Res. 198, 30-34. doi: 10.1016/j.virusres.2015.01.002

Fischer, M. G., and Hackl, T. (2016). Host genome integration and giant virusinduced reactivation of the virophage mavirus. Nature 540, 288-291. doi: 10. 1038/nature20593

Fischer, M. G., and Suttle, C. A. (2011). A virophage at the origin of large DNA transposons. Science 332, 231-234. doi: 10.1126/science.1199412

Flores, R., Gago-Zachert, S., Serra, P., Sanjuán, R., and Elena, S. F. (2014). Viroids: survivors from the RNA world? Annu. Rev. Microbiol. 68, 395-414. doi: 10. 1146/annurev-micro-091313-103416

Friedrich-Loeffler-Institut. (2018). Humane infektionen mit dem borna disease virus (BoDV-1) [in German]. Epid. Bull. 10:105.

Fujino, K., Horie, M., Honda, T., Merriman, D. K., and Tomonaga, K. (2014). Inhibition of Borna disease virus replication by an endogenous bornaviruslike element in the ground squirrel genome. Proc. Natl. Acad. Sci. U.S.A. 111, 13175-13180. doi: 10.1073/pnas.1407046111

Furuta, Y., Abe, K., and Kobayashi, I. (2010). Genome comparison and context analysis reveals putative mobile forms of restriction-modification systems and related rearrangements. Nucleic Acids Res. 38, 2428-2443. doi: 10.1093/nar/ gkp1226

Ghildiyal, M., Seitz, H., Horwich, M. D., Li, C., Du, T., Lee, S., et al. (2008). Endogenous siRNAs derived from transposons and mRNAs in Drosophila somatic cells. Science 320, 1077-1081. doi: 10.1126/science. 1157396

Gifford, R., and Tristem, M. (2003). The evolution, distribution and diversity of endogenous retroviruses. Virus Genes 26, 291-315. doi: 10.1023/A: 1024455415443

Gifford, R. J., Katzourakis, A., Tristem, M., Pybus, O. G., Winters, M., and Shafer, R. W. (2008). A transitional endogenous lentivirus from the genome of a basal primate and implications for lentivirus evolution. Proc. Natl. Acad. Sci. U.S.A. 105, 20362-20367. doi: 10.1073/pnas.0807873105

Gilbert, C., Maxfield, D. G., Goodman, S. M., and Feschotte, C. (2009). Parallel germline infiltration of a lentivirus in two Malagasy lemurs. PLoS Genet. 5:e1000425. doi: 10.1371/journal.pgen.1000425

Goldfarb, T., Sberro, H., Weinstock, E., Cohen, O., Doron, S., CharpakAmikam, Y., et al. (2015). BREX is a novel phage resistance system widespread in microbial genomes. EMBO J. 34, 169-183. doi: 10.15252/embj.2014 89455

Gonzalez-Hernandez, M. J., Swanson, M. D., Contreras-Galindo, R., Cookinham, S., King, S. R., Noel, R. J. Jr., et al. (2012). Expression of human endogenous retrovirus type K (HML-2) is activated by the Tat protein of HIV-1. J. Virol. 86, 7790-7805. doi: 10.1128/JVI.07215-11

Grandi, N., Cadeddu, M., Pisano, M. P., Esposito, F., Blomberg, J., and Tramontano, E. (2017). Identification of a novel HERV-K(HML10): comprehensive characterization and comparative analysis in non-human primates provide insights about HML10 proviruses structure and diffusion. Mob. DNA 8:15. doi: 10.1186/s13100-017-0099-7

Grow, E. J., Flynn, R. A., Chavez, S. L., Bayless, N. L., Wossidlo, M., Wesche, D. J., et al. (2015). Intrinsic retroviral reactivation in human preimplantation embryos and pluripotent cells. Nature 522, 221-225. doi: 10.1038/nature 14308

Han, G. Z., and Worobey, M. (2012). Endogenous lentiviral elements in the weasel family (Mustelidae). Mol. Biol. Evol. 29, 2905-2908. doi: 10.1093/molbev/ mss126

Han, G. Z., and Worobey, M. (2015). A primitive endogenous lentivirus in a colugo: insights into the early evolution of lentiviruses. Mol. Biol. Evol. 32, 211-215. doi: 10.1093/molbev/msu297

Haraguchi, S., Good, R. A., Cianciolo, G. J., Engelman, R. W., and Day, N. K. (1997). Immunosuppressive retroviral peptides: immunopathological implications for immunosuppressive influences of retroviral infections. J. Leukoc. Biol. 61, 654-666. doi: 10.1002/jlb.61.6.654

Haraguchi, S., Good, R. A., and Day-Good, N. K. (2008). A potent immunosuppressive retroviral peptide: cytokine patterns and signaling pathways. Immunol. Res. 41, 46-55. doi: 10.1007/s12026-0070039-6

Haraguchi, S., Good, R. A., James-Yarish, M., Cianciolo, G. J., and Day, N. K. (1995). Differential modulation of Th1- and Th2-related cytokine mRNA expression by a synthetic peptide homologous to a conserved domain within retroviral envelope protein. Proc. Natl. Acad. Sci. U.S.A. 92, 3611-3615. doi: $10.1073 /$ pnas.92.8.3611

Hartley, J. W., Yetter, R. A., and Morse, H. C. III (1983). A mouse gene on chromosome 5 that restricts infectivity of mink cell focus-forming recombinant murine leukemia viruses. J. Exp. Med. 158, 16-24. doi: 10.1084/jem. 158.1.16

Hille, F., Richter, H., Wong, S. P., Bratoviè, M., Ressel, S., and Charpentier, E. (2018). The biology of CRISPR-Cas: backward and forward. Cell 172, 1239-1259. doi: 10.1016/j.cell.2017.11.032

Himmel, D. M., Sarafianos, S. G., Dharmasena, S., Hossain, M. M., McCoySimandle, K., Ilina, T., et al. (2006). HIV-1 reverse transcriptase structure with RNase $\mathrm{H}$ inhibitor dihydroxy benzoyl naphthyl hydrazone bound at a novel site. ACS Chem. Biol. 1, 702-712. doi: 10.1021/cb600303y

Hoffmann, B., Tappe, D., Höper, D., Herden, C., Boldt, A., Mawrin, C., et al. (2015). A variegated squirrel bornavirus associated with fatal human encephalitis. N. Engl. J. Med. 373, 154-162. doi: 10.1056/NEJMoa1415627

Horie, M. (2017). The biological significance of bornavirus-derived genes in mammals. Curr. Opin. Virol. 25, 1-6. doi: 10.1016/j.coviro.2017.06.004 
Horie, M., Honda, T., Suzuki, Y., Kobayashi, Y., Daito, T., Oshida, T., et al. (2010). Endogenous non-retroviral RNA virus elements in mammalian genomes. Nature 463, 84-87. doi: 10.1038/nature08695

Horton, R., Wilming, L., Rand, V., Lovering, R. C., Bruford, E. A., Khodiyar, V. K., et al. (2004). Gene map of the extended human MHC. Nat. Rev. Genet. 5, 889-899. doi: 10.1038/nrg1489

Hyndman, T. H., Shilton, C. M., Stenglein, M. D., and Wellehan, J. F. X. Jr. (2018). Divergent bornaviruses from Australian carpet pythons with neurological disease date the origin of extant Bornaviridae prior to the end-Cretaceous extinction. PLoS Pathog. 14:e1006881. doi: 10.1371/journal.ppat.1006881

Ikeda, H., Laigret, F., Martin, M. A., and Repaske, R. (1985). Characterization of a molecularly cloned retroviral sequence associated with $\mathrm{Fv}-4$ resistance. J. Virol. $55,768-777$.

Imakawa, K., and Nakagawa, S. (2017). The phylogeny of placental evolution through dynamic integrations of retrotransposons. Prog. Mol. Biol. Transl. Sci. 145, 89-109. doi: 10.1016/bs.pmbts.2016.12.004

Iranzo, J., Cuesta, J. A., Manrubia, S., Katsnelson, M. I., and Koonin, E. V. (2017). Disentangling the effects of selection and loss bias on gene dynamics. Proc. Natl. Acad. Sci. U.S.A. 114, E5616-E5624. doi: 10.1073/pnas.1704925114

Ito, J., Sugimoto, R., Nakaoka, H., Yamada, S., Kimura, T., Hayano, T., et al. (2017). Systematic identification and characterization of regulatory elements derived from human endogenous retroviruses. PLoS Genet. 13:e1006883. doi: 10.1371/journal.pgen.1006883

Ito, J., Watanabe, S., Hiratsuka, T., Kuse, K., Odahara, Y., Ochi, H., et al. (2013). Refrex-1, a soluble restriction factor against feline endogenous and exogenous retroviruses. J. Virol. 87, 12029-12040. doi: 10.1128/JVI.01267-13

Iwasaki, Y. W., Siomi, M. C., and Siomi, H. (2015). PIWI-interacting RNA: its biogenesis and functions. Annu. Rev. Biochem. 84, 405-433. doi: 10.1146/ annurev-biochem-060614-034258

Jeltsch, A., Kröger, M., and Pingoud, A. (1995). Evidence for an evolutionary relationship among type-II restriction endonucleases. Gene 160, 7-16. doi: 10. 1016/0378-1119(95)00181-5

Jeltsch, A., and Pingoud, A. (1996). Horizontal gene transfer contributes to the wide distribution and evolution of type II restriction-modification systems. J. Mol. Evol. 42, 91-96. doi: 10.1007/BF02198833

Jimenez, R. M., Polanco, J. A., and Lupták, A. (2015). Chemistry and biology of self-cleaving ribozymes. Trends Biochem. Sci. 40, 648-661. doi: 10.1016/j.tibs. 2015.09.001

Jung, Y. T., Lyu, M. S., Buckler-White, A., and Kozak, C. A. (2002). Characterization of a polytropic murine leukemia virus proviral sequence associated with the virus resistance gene Rmcf of DBA/2 mice. J. Virol. 76, 8218-8224. doi: 10.1128/JVI.76.16.8218-8224.2002

Kapitonov, V. V., and Koonin, E. V. (2015). Evolution of the RAG1-RAG2 locus: both proteins came from the same transposon. Biol. Direct 10:20. doi: 10.1186/ s13062-015-0055-8

Katzourakis, A., and Gifford, R. J. (2010). Endogenous viral elements in animal genomes. PLoS Genet. 6:e1001191. doi: 10.1371/journal.pgen.1001191

Katzourakis, A., Tristem, M., Pybus, O. G., and Gifford, R. J. (2007). Discovery and analysis of the first endogenous lentivirus. Proc. Natl. Acad. Sci. U.S.A. 104, 6261-6265. doi: 10.1073/pnas.0700471104

Kent, W. J., Sugnet, C. W., Furey, T. S., Roskin, K. M., Pringle, T. H., Zahler, A. M., et al. (2002). The human genome browser at UCSC. Genome Res. 12, 996-1006. doi: 10.1101/gr.229102

Khan, F., Furuta, Y., Kawai, M., Kaminska, K. H., Ishikawa, K., Bujnicki, J. M., et al. (2010). A putative mobile genetic element carrying a novel type IIF restriction-modification system (PluTI). Nucleic Acids Res. 38, 3019-3030. doi: 10.1093/nar/gkp1221

Kobayashi, Y., Horie, M., Nakano, A., Murata, K., Itou, T., and Suzuki, Y. (2016). Exaptation of bornavirus-like nucleoprotein elements in afrotherians. PLoS Pathog. 12:e1005785. doi: 10.1371/journal.ppat.1005785

Koonin, E. V. (2018). Hunting for treasure chests in microbial defense Islands. Mol. Cell 70, 761-762. doi: 10.1016/j.molcel.2018.05.025

Koonin, E. V., and Dolja, V. V. (2014). Virus world as an evolutionary network of viruses and capsidless selfish elements. Microbiol. Mol. Biol. Rev. 78, 278-303. doi: 10.1128/MMBR.00049-13

Koonin, E. V., and Krupovic, M. (2015). Evolution of adaptive immunity from transposable elements combined with innate immune systems. Nat. Rev. Genet. 16, 184-192. doi: 10.1038/nrg3859
Koonin, E. V., and Krupovic, M. (2018). The depths of virus exaptation. Curr. Opin. Virol. 31, 1-8. doi: 10.1016/j.coviro.2018.07.011

Koonin, E. V., and Makarova, K. S. (2017). Mobile genetic elements and evolution of CRISPR-Cas systems: all the way there and back. Genome Biol. Evol. 9, 2812-2825. doi: 10.1093/gbe/evx192

Kovalskaya, N., and Hammond, R. W. (2014). Molecular biology of viroid-host interactions and disease control strategies. Plant Sci. 228, 48-60. doi: 10.1016/j. plantsci.2014.05.006

Krupovic, M., Makarova, K. S., Forterre, P., Prangishvili, D., and Koonin, E. V. (2014). Casposons: a new superfamily of self-synthesizing DNA transposons at the origin of prokaryotic CRISPR-Cas immunity. BMC Biol. 12:36. doi: 10.1186/ 1741-7007-12-36

Lavialle, C., Cornelis, G., Dupressoir, A., Esnault, C., Heidmann, O., Vernochet, C., et al. (2013). Paleovirology of 'syncytins', retroviral env genes exapted for a role in placentation. Philos. Trans. R. Soc. Lond. B Biol. Sci. 368:20120507. doi: $10.1098 /$ rstb.2012.0507

Lee, E. J., Banerjee, S., Zhou, H., Jammalamadaka, A., Arcila, M., Manjunath, B. S., et al. (2011). Identification of piRNAs in the central nervous system. RNA 17, 1090-1099. doi: 10.1261/rna.2565011

Li, Y., Basavappa, M., Lu, J., Dong, S., Cronkite, D. A., Prior, J. T., et al. (2016). Induction and suppression of antiviral RNA interference by influenza A virus in mammalian cells. Nat. Microbiol. 2:16250. doi: 10.1038/nmicrobiol. 2016.250

Lima, W. F., Wu, H., Nichols, J. G., Sun, H., Murray, H. M., and Crooke, S. T. (2009). Binding and cleavage specificities of human Argonaute2. J. Biol. Chem. 284, 26017-26028. doi: 10.1074/jbc.M109.010835

Löber, U., Hobbs, M., Dayaram, A., Tsangaras, K., Jones, K., AlquezarPlanas, D. E., et al. (2018). Degradation and remobilization of endogenous retroviruses by recombination during the earliest stages of a germ-line invasion. Proc. Natl. Acad. Sci. U.S.A. 115, 8609-8614. doi: 10.1073/pnas.18075 98115

Ma, B. G., Chen, L., Ji, H. F., Chen, Z. H., Yang, F. R., Wang, L., et al. (2008). Characters of very ancient proteins. Biochem. Biophys. Res. Commun. 366, 607-611. doi: 10.1016/j.bbrc.2007.12.014

Mack, M., Bender, K., and Schneider, P. M. (2004). Detection of retroviral antisense transcripts and promoter activity of the HERV-K(C4) insertion in the MHC class III region. Immunogenetics 56, 321-332. doi: 10.1007/s00251-0040705-y

Maillard, P. V., Ciaudo, C., Marchais, A., Li, Y., Jay, F., Ding, S. W., et al. (2013). Antiviral RNA interference in mammalian cells. Science 342, 235-238. doi: $10.1126 /$ science. 1241930

Maillard, P. V., Van der Veen, A. G., Deddouche-Grass, S., Rogers, N. C., Merits, A., Reis, E., et al. (2016). Inactivation of the type I interferon pathway reveals long double-stranded RNA-mediated RNA interference in mammalian cells. EMBO J. 35, 2505-2518. doi: 10.15252/embj.201695086

Majorek, K. A., Dunin-Horkawicz, S., Steczkiewicz, K., Muszewska, A., Nowotny, M., Ginalski, K., et al. (2014). The RNase H-like superfamily: new members, comparative structural analysis and evolutionary classification. Nucleic Acids Res. 42, 4160-4179. doi: 10.1093/nar/gkt1414

Makarova, K. S., Wolf, Y. I., Snir, S., and Koonin, E. V. (2011). Defense islands in bacterial and archaeal genomes and prediction of novel defense systems. J. Bacteriol. 193, 6039-6056. doi: 10.1128/JB.05535-11

Makarova, K. S., Zhang, F., and Koonin, E. V. (2017). SnapShot: class 2 CRISPR-Cas systems. Cell 168, 328-328.e1. doi: 10.1016/j.cell.2016.12.038

Malfavon-Borja, R., and Feschotte, C. (2015). Fighting fire with fire: endogenous retrovirus envelopes as restriction factors. J. Virol. 89, 4047-4050. doi: 10.1128/ JVI.03653-14

Matskevich, A. A., and Moelling, K. (2007). Dicer is involved in protection against influenza A virus infection. J. Gen. Virol. 88, 2627-2635. doi: 10.1099/vir.0. 83103-0

McKinney, H. H. (1929). Mosaic diseases in the Canary Islands, West Africa and Gibraltar. J. Agric. Res. 39, 557-578.

Moelling, K., Abels, S., Jendis, J., Matskevich, A., and Heinrich, J. (2006a). Silencing of HIV by hairpin-loop-structured DNA oligonucleotide. FEBS Lett. 580, 3545-3550.

Moelling, K., Matskevich, A., and Jung, J. S. (2006b). Relationship between retroviral replication and RNA interference machineries. Cold Spring Harb. Symp. Quant. Biol. 71, 365-368. 
Moelling, K., and Broecker, F. (2015). The reverse transcriptase-RNase H: from viruses to antiviral defense. Ann. N. Y. Acad. Sci. 1341, 126-135. doi: 10.1111/ nyas. 12668

Moelling, K., Broecker, F., Russo, G., and Sunagawa, S. (2017). RNase H as gene modifier, driver of evolution and antiviral defense. Front. Microbiol. 8:1745. doi: $10.3389 /$ fmicb.2017.01745

Mölling, K., Bolognesi, D. P., Bauer, H., Büsen, W., Plassmann, H. W., and Hausen, P. (1971). Association of viral reverse transcriptase with an enzyme degrading the RNA moiety of RNA-DNA hybrids. Nat. New Biol. 234, 240-243. doi: 10.1038/newbio234240a0

Monde, K., Terasawa, H., Nakano, Y., Soheilian, F., Nagashima, K., Maeda, Y., et al. (2017). Molecular mechanisms by which HERV-K Gag interferes with HIV-1 Gag assembly and particle infectivity. Retrovirology 14:27. doi: 10.1186/s12977017-0351-8

Murphy, J., Mahony, J., Ainsworth, S., Nauta, A., and van Sinderen, D. (2013). Bacteriophage orphan DNA methyltransferases: insights from their bacterial origin, function, and occurrence. Appl. Environ. Microbiol. 79, 7547-7555. doi: 10.1128/AEM.02229-13

Naderer, M., Brust, J. R., Knowle, D., and Blumenthal, R. M. (2002). Mobility of a restriction-modification system revealed by its genetic contexts in three hosts. J. Bacteriol. 184, 2411-2419. doi: 10.1128/JB.184.9.2411-2419.2002

Nagamalleswari, E., Rao, S., Vasu, K., and Nagaraja, V. (2017). Restriction endonuclease triggered bacterial apoptosis as a mechanism for long time survival. Nucleic Acids Res. 45, 8423-8434. doi: 10.1093/nar/gkx576

Nandi, S., Chandramohan, D., Fioriti, L., Melnick, A. M., Hébert, J. M., Mason, C. E., et al. (2016). Roles for small noncoding RNAs in silencing of retrotransposons in the mammalian brain. Proc. Natl. Acad. Sci. U.S.A. 133, 12697-12702. doi: 10.1073/pnas.1609287113

Nuovo, G. J., Becker, J., Simsir, A., Margiotta, M., Khalife, G., and Shevchuk, M. (1994). HIV-1 nucleic acids localize to the spermatogonia and their progeny. A study by polymerase chain reaction in situ hybridization. Am. J. Pathol. 144, 1142-1148.

Ofir, G., Melamed, S., Sberro, H., Mukamel, Z., Silverman, S., Yaakov, G., et al. (2017). DISARM is a widespread bacterial defence system with broad antiphage activities. Nat. Microbiol. 3, 90-98. doi: 10.1038/s41564-017-0051-0

Oliveira, N. M., Satija, H., Kouwenhoven, I. A., and Eiden, M. V. (2007). Changes in viral protein function that accompany retroviral endogenization. Proc. Natl. Acad. Sci. U.S.A. 104, 17506-17511. doi: 10.1073/pnas.0704313104

Palmarini, M., Mura, M., and Spencer, T. E. (2004). Endogenous betaretroviruses of sheep: teaching new lessons in retroviral interference and adaptation. J. Gen. Virol. 85, 1-13. doi: 10.1099/vir.0.19547-0

Parrish, N. F., Fujino, K., Shiromoto, Y., Iwasaki, Y. W., Ha, H., Xing, J., et al. (2015). piRNAs derived from ancient viral processed pseudogenes as transgenerational sequence-specific immune memory in mammals. RNA 21, 1691-1703. doi: 10.1261/rna.052092.115

Pettersen, E. F., Goddard, T. D., Huang, C. C., Couch, G. S., Greenblatt, D. M., Meng, E. C., et al. (2004). UCSF Chimera-a visualization system for exploratory research and analysis. J. Comput. Chem. 25, 1605-1612. doi: 10.1002/jcc.20084

Planz, O., and Stitz, L. (1999). Borna disease virus nucleoprotein (p40) is a major target for $\mathrm{CD}^{+}{ }^{+}$-T-cell-mediated immune response. J. Virol. 73, 1715-1718.

Qiu, Y., Xu, Y., Zhang, Y., Zhou, H., Deng, Y. Q., Li, X. F., et al. (2017). Human virus-derived small RNAs can confer antiviral immunity in mammals. Immunity 46, 992-1004. doi: 10.1016/j.immuni.2017.05.006

Schneider, P. M., Witzel-Schlömp, K., Rittner, C., and Zhang, L. (2001). The endogenous retroviral insertion in the human complement $\mathrm{C} 4$ gene modulates the expression of homologous genes by antisense inhibition. Immunogenetics 53, 1-9. doi: 10.1007/s002510000288

Seed, K. D., Lazinski, D. W., Calderwood, S. B., and Camilli, A. (2013). A bacteriophage encodes its own CRISPR/Cas adaptive response to evade host innate immunity. Nature 494, 489-491. doi: 10.1038/nature1 1927

Shabalina, S. A., and Koonin, E. V. (2008). Origins and evolution of eukaryotic RNA interference. Trends Ecol. Evol. 23, 578-587. doi: 10.1016/j.tree.2008. 06.005

Smit, A. F. A., Hubley, R., and Green, P. (2013-2015). RepeatMasker Open-4.0. Available at: http://www.repeatmasker.org

Sofuku, K., Parrish, N. F., Honda, T., and Tomonaga, K. (2015). Transcription profiling demonstrates epigenetic control of non-retroviral RNA virus-derived elements in the human genome. Cell Rep. 12, 1548-1554. doi: 10.1016/j.celrep. 2015.08.007

Song, J. J., Smith, S. K., Hannon, G. J., and Joshua-Tor, L. (2004). Crystal structure of Argonaute and its implications for RISC slicer activity. Science 305, 1434-1437. doi: 10.1126/science.1102514

Spencer, T. E., Mura, M., Gray, C. A., Griebel, P. J., and Palmarini, M. (2003). Receptor usage and fetal expression of ovine endogenous betaretroviruses: implications for coevolution of endogenous and exogenous retroviruses. J. Virol. 77, 749-753. doi: 10.1128/JVI.77.1.749-753.2003

Stetson, D. B., Ko, J. S., Heidmann, T., and Medzhitov, R. (2008). Trex1 prevents cell-intrinsic initiation of autoimmunity. Cell 134, 587-598. doi: 10.1016/j.cell. 2008.06.032

Stoye, J. P. (2006). Koala retrovirus: a genome invasion in real time. Genome Biol. 7:241. doi: 10.1186/gb-2006-7-11-241

Suzuki, S. (1975). FV-4: a new gene affecting the splenomegaly induction by Friend leukemia virus. Jpn. J. Exp. Med. 45, 473-478.

Suzuki, Y., Frangeul, L., Dickson, L. B., Blanc, H., Verdier, Y., Vinh, J., et al. (2017). Uncovering the repertoire of endogenous flaviviral elements in aedes mosquito genomes. J. Virol. 91:e00571-17. doi: 10.1128/JVI.00571-17

Suzuki, Y., Kobayashi, Y., Horie, M., and Tomonaga, K. (2014). Origin of an endogenous bornavirus-like nucleoprotein element in thirteenlined ground squirrels. Genes Genet. Syst. 89, 143-148. doi: 10.1266/ggs. 89.143

Swarts, D. C., Makarova, K., Wang, Y., Nakanishi, K., Ketting, R. F., Koonin, E. V., et al. (2014). The evolutionary journey of Argonaute proteins. Nat. Struct. Mol. Biol. 21, 743-753. doi: 10.1038/nsmb.2879

Takahashi, N., Ohashi, S., Sadykov, M. R., Mizutani-Ui, Y., and Kobayashi, I. (2011). IS-linked movement of a restriction-modification system. PLoS One 6:e16554. doi: 10.1371/journal.pone.0016554

Tarlinton, R. E., Meers, J., and Young, P. R. (2006). Retroviral invasion of the koala genome. Nature 442, 79-81. doi: 10.1038/nature04841

Tarlinton, R. E., Sarker, N., Fabijan, J., Dottorini, T., Woolford, L., Meers, J., et al. (2017). Differential and defective expression of Koala Retrovirus reveal complexity of host and virus evolution. bioRxiv Available at: https://www. biorxiv.org/content/early/2017/11/09/211466 [accessed July 28, 2018].

tenOever, B. R. (2017). Questioning antiviral RNAi in mammals. Nat. Microbiol. 2:17052. doi: 10.1038/nmicrobiol.2017.52

Terry, S. N., Manganaro, L., Cuesta-Dominguez, A., Brinzevich, D., Simon, V., and Mulder, L. C. F. (2017). Expression of HERV-K108 envelope interferes with HIV-1 production. Virology 509, 52-59. doi: 10.1016/j.virol.2017. 06.004

Tsai, K., Courtney, D. G., Kennedy, E. M., and Cullen, B. R. (2018). Influenza A virus-derived siRNAs increase in the absence of NS1 yet fail to inhibit virus replication. RNA 24, 1172-1182. doi: 10.1261/rna. 066332.118

Van't Hof, A. E., Campagne, P., Rigden, D. J., Yung, C. J., Lingley, J., Quail, M. A., et al. (2016). The industrial melanism mutation in British peppered moths is a transposable element. Nature 534, 102-105. doi: 10.1038/nature 17951

Wang, M., Boca, S. M., Kalelkar, R., Mittenthal, J. E., and Caetano-Anollés, G. (2006). A phylogenomic reconstruction of the protein world based on a genomic census of protein fold architecture. Complexity 12, 27-40. doi: 10.1002/ cplx.20141

Wang, X., Kim, Y., Ma, Q., Hong, S. H., Pokusaeva, K., Sturino, J. M., et al. (2010). Cryptic prophages help bacteria cope with adverse environments. Nat. Commun. 1:147. doi: 10.1038/ncomms1146

Waugh, C., Gillett, A., Polkinghorne, A., and Timms, P. (2016). Serum antibody response to koala retrovirus antigens varies in free-ranging koalas (Phascolarctos cinereus) in Australia: implications for vaccine design. J. Wildl. Dis. 52, 422-425. doi: 10.7589/2015-09-257

Weinberger, A. D., Sun, C. L., Pluciñski, M. M., Denef, V. J., Thomas, B. C., Horvath, P., et al. (2012). Persisting viral sequences shape microbial CRISPRbased immunity. PLoS Comput. Biol. 8:e1002475. doi: 10.1371/journal.pcbi. 1002475

Weiss, R. A. (2006). The discovery of endogenous retroviruses. Retrovirology 3:67. Yang, Y., Chung, E. K., Zhou, B., Blanchong, C. A., Yu, C. Y., Füst, G., et al. (2003). Diversity in intrinsic strengths of the human complement system: serum C4 protein concentrations correlate with $\mathrm{C} 4$ gene size and polygenic variations, 
hemolytic activities, and body mass index. J. Immunol. 171, 2734-2745. doi: 10.4049/jimmunol.171.5.2734

Yang, Y. G., Lindahl, T., and Barnes, D. E. (2007). Trex1 exonuclease degrades ssDNA to prevent chronic checkpoint activation and autoimmune disease. Cell 131, 873-886. doi: 10.1016/j.cell.2007.10.017

Yuan, Y. R., Pei, Y., Ma, J. B., Kuryavyi, V., Zhadina, M., Meister, G., et al. (2005). Crystal structure of A. aeolicus argonaute, a site-specific DNA-guided endoribonuclease, provides insights into RISC-mediated mRNA cleavage. Mol. Cell 19, 405-419. doi: 10.1016/j.molcel.2005. 07.011
Conflict of Interest Statement: The authors declare that the research was conducted in the absence of any commercial or financial relationships that could be construed as a potential conflict of interest.

Copyright $\odot 2019$ Broecker and Moelling. This is an open-access article distributed under the terms of the Creative Commons Attribution License (CC BY). The use, distribution or reproduction in other forums is permitted, provided the original author(s) and the copyright owner(s) are credited and that the original publication in this journal is cited, in accordance with accepted academic practice. No use, distribution or reproduction is permitted which does not comply with these terms. 